\title{
Problematic Areas in Writing Skills: Introducing Triplet Method to Analyze the English Language Writing Problems at Secondary Level Classes in Pakistan
}

\author{
*Corresponding Author \\ Hassan Bin Zubair

\section{Article History} \\ Received: 22.07 .2019 \\ Accepted: 12.08 .2019 \\ Published: 30.08 .2019
}

Hassan Bin Zubair ${ }^{1 *}$, Dr. Fakhra Aziz²

1PhD Scholar (English Literature), Department of English National University of Modern Languages, Islamabad, Pakistan

${ }^{2}$ Assistant Professor Institute of Education, Lahore College for Women University, Lahore, Pakistan

\begin{abstract}
This research explores the major problematic areas of writing at secondary level. Mostly student face the difficulty in different areas of the language rules and its usage but the most common problematic area is the grammatical area. Spelling mistakes, using inappropriate vocabulary, translation problems and problems with information organization are common among the students. The researcher used three tools in this research; class observation, students' interview and assessment of students' writing. These three tools were essential in finding out various writing problems different students experienced. I name it the "Triplet Method" to analyze the problematic areas in English language writing skill. Observing various classes, conducting numerous interviews and assessing scripts have all resulted in the authentic collection of information and a successful undertaking of the research. Moreover teachers' speech was also recorded in a mobile phone. For data analysis, researcher observed three different classes of three different schools, from where 30 scripts accessed and took 30 interviews. Findings of the collected data show that writing problems are not due the inabilities of the students but the education system is also responsible for its drawback. This paper concludes with scopes for future research and investigations.
\end{abstract}

Keywords: English Language, Grammatical Problems, Activity, Urdu Language, Content.

\section{INTRODUCTION}

Writing is one of the most popular way of expressing emotions and thoughts. Through writing people can take time and can state their emotions clearly. Moreover, writing tasks are applied broadly during language practice for learning foreign languages. Yet, students of all levels face many problems while writing any task. Though writing is one of the best ways of expressing thoughts, students often cannot make sense or convey the meaning to the reader through their writing tasks. Tirumalesh suggested some reasons why people have limited knowledge about English writing. "Lack of proficiency in the language, large classes, unqualified teachers, unmotivated novices, lack of resources became the part of the etiology. From his point of view, the problem can be solved by mobilizing more materials or by an appropriate use of the existing resources [1]". Moreover, at secondary level, students of Urdu medium school believe that grammatical errors hinder their writing performance more than any other problems in their second language classes. However there are many other factors which are responsible for creating writing problems in second language classes. The purpose of this study is to explore Urdu medium students' writing problems through class observation, interview and script checking of the students. Ur [2] identified that the purpose and principle of writing skill is to express ideas and convey the message to the reader. Moreover, the writers should be aware of some formal aspects such as, neat hand writing, correct spellings, proper use of punctuation and vocabulary and acceptable grammar. These aspects are needed because in higher standards of language are usually demanded in writing than in speech. He also mentioned that more careful construction, more precise and varied vocabulary, more correctness of expression is also the important aspects of wring.

"When a student submits a piece of original writing then the most important

thing is to see whether the ideas and events presented there is interesting

and significant or not. In addition, the writer should organize his thoughts

and ideas and present them through his writing in a way so that the readers

can read that easily and feel pleased to read that. However, one of the

Copyright @ 2019: This is an open-access article distributed under the terms of the Creative Commons Attribution license which permits unrestricted use, distribution, and reproduction in any medium for non commercial use (NonCommercial, or CC-BY-NC) provided the original author and source are credited. 
problems in teaching writing is maintaining a fair balance between content and forms [2]".

Widodo [3] stated that a genre based approach to teaching L2 writing focuses on the gatherings of an individual text type and try to help students to understand what is the purpose of writing text, who is their audience or for whom they are writing and how to organize a text [4]. Manchón [5] believed that writing is used widely in language practice for learning foreign language. For this reason scholars made a difference between writing to learn contentand writing to learn language. Moreover, it is clear that all types of writing in foreign language education contribute to the progress of language skills. Both learning-to-write and writing-to-learn tasks help to develop the learners' foreign language skill [6]. Coe and Gutierrez [7] identified some principles for the learners to find out their writing problems, to set their goals and to evaluate their progress.

- Changing the process is the best way to improve the quality of written product.

- In case of developing writing skill, active learning is more useful than passive learning and goals which are set by the students are more prone to be achieved than the goals required by the teachers.

- Students can learn significantly from fellow students.

- Identifying the exact problem can lead to solve the problem successfully.

- Stating goal accurately, applying the best strategy, maintaining a perfect time frame and the ability of verifying the procedure will ensure to achieve the goal [7].

\section{Research Objectives}

- To find out the major areas which create problems in learning writing skills.

- To highlight the grey areas of teaching and methodologies at school.

- To present the solutions to overcome the problems faced by the students while learning writing skills.

\section{RESEARCH QUESTIONS}

Using three different formats such as, class observation, students' interview and scripts assessment the researcher tried to discover the answers of the research questions below.

- What are the main hurdles while learning writing techniques/skills?

- What measures can be taken to overcome the English language writing problems at secondary school level in Pakisan?

- How a teacher can play his/her positive role in teaching writing techniques in a positive and more comprehensive manner?

- What is the role of an institution and syllabus for providing better understanding in learning process of writing skills?

\section{Methods Applied in Writing Classes \\ (i) Grammar Translation Method}

Freeman [8] claimed that Grammar Translation Method focuses only teaching and learning the rules. From GTM perspective learning a language means learning all grammatical rules. In GTM accuracy is more important than fluency. Students need to learn all grammatical items correctly they do not need to be fluent in the use of grammar while talking. In GTM method deductive learning is a must, student need to learn rules and definitions first and later they learn examples. Through this method student can learn grammatical rules correctly and they do well in writing. He also claimed that this method is good for beginners and for large classes also, it required fewer resources. On the other hand, in this method the teacher is the authoritative figure to make decisions and the participation of learners is very less.
"Although the Grammar-Translation Method often creates frustration for students, it makes few demands on teachers. It is still used in situations where understanding literary texts is the primary focus of foreign language study and there is little need for a speaking knowledge of the language." [8].

\section{(ii) The Audio-Lingual Method}

Freeman [8] claimed that there is dependence on imitation, memorization language and over learning. It drills students in the use of grammatical sentence pattern. This method talks about habit formation. The more students will repeat the more they will learn. They make errors due to the formation of bad habit; errors should be corrected immediately by the teacher. Positive reinforcement helps students to build right habits. Grammatical rules are taught by inductive learning rather than deductive learning.

\section{Writing Problems}

There are two categories of writing mistakes; one is error characteristics and the other is non-error characteristics. The teachers can simply find out error characteristics from students' writing. There are eight major problems that students face in error 
characteristics and they are, spelling problems, pronoun usage, agreement between subject and predicate, the avoidance of run-on sentence, capitalization, punctuation, usage of slang or nonstandard terms and modification problems. But if there is no mistake in writing still that particular writing cannot be considered as a good piece of writing. "There are some no error characteristics which make difference between skilled writing and non-skilled writing and they are density of ideas, variety of referents and variety of expression in repeated concepts" [9]. Writing is just not expressing thought it is also conveying the thoughts to the reader, therefore writings should be meaningful. Flower pointed out a question that is, if writing is considered as the act of what the writer thinks or what the writer means then why writing is such a hard thing to do or why writers fail to communicate with the readers. The author also mentioned that writers' mental struggle and readers' misinterpretation prove that writing is justnot expressing what writers think or means it is more than that. From the authors perspective writing is just not expressing the thoughts but also transferring the thought to the readers. "Some common problems in academic and professional writing is the absence of referent, immature and imprecise ideas, some senseless discussions and being unsuccessful to convert private thoughts into a public [10]".

Students' writing performances often depend on teachers. If the teachers give the students more writing tasks and make them practice writing tasks several times then students can develop their writing skill. Evans [11] said that in school it is very common that the quality of students' writings depend on teachers' expectation. If the students were given more writing task like assignments and reports on a particular topic or themes then the students would get more opportunity to write and practice. He also stated that "students' writing will be more matured as long as they will practice writing on narrowed topics and work on outlines and organize materials [11]". Grammatical correctness is not compulsory to communicate with the readers through writing. Most of the foreign language teachers give importance on grammatical accuracy which is not a mandatory issue in ESL classes. Holley and King [12] stated that even though grammatical correctness is not always compulsory of an ESL student to achieve communication, teachers of ESL have persisted for many years on grammatical correctness in student performance. Foreign language teachers have been trained to correct students' inappropriate response instantly when it is about grammatical and pronunciation errors, because it is being assumed that correcting errors instantly will help to learn. Teachers who emphasis more on grammatical accuracy they might not encourage students when they are communicating in foreign language [13]. Teachers should give the attention to the each students based on the students' needs. Moreover, teachers should make the students clear about the subject matters; if they do so then it will help the students to find their own problems. Lagerberg emphasized on some issues like, in foreign language teaching classrooms teachers think that the metalanguage they use to teach students is understood by them which is a big mistake.

"Weaker students need more clarification and examples to get into the topic. Moreover, students need to be cleared about the topic which is taught to Them by themselves first and then they can find out their own problems by Themselves. Another problem is teachers try to make the students accurate In terms of using grammatical rules [14]".

\section{Research Methodology}

The primary focus of the researcher is to identify various types of writing problems experienced by students and also to understand the reason behind such problems. The research is based on public sector schools in Pakistan. The data to be examined in this paper is obtained by the researcher from public sector schools. The number of students was large in almost every class. Most classes had a typical classroom setting with seating arrangements for students facing a black board, table and chair where a teacher usually took his/her position. The teachers did ample movement during the lectures explaining various topics and also providing individual attention to students and their queries. The researcher was seated strategically in order to clearly hear the teachers and at the same time effectively observe the students. There was a sound learning atmosphere as the environment of the classrooms was very good with sufficient air, light and space.

\section{NATURE OF RESEARCH}

In this research the researcher applied two types of research methodology. So the nature of research was mixed. The researcher's observation included detailed explanation of what the various classes were all about. Based on the output received, the researcher had to draw a connection between what was being taught in class and the students learned, understood and could inculcate. Moreover there were interviews of students where most of the questions were open ended and students had to describe their opinions to the researcher. Moreover, the researcher has checked some of the scripts of the students and stated their problems of writing by explaining some facts. Hence, the detailed opinions and in-depth explanation of the research gives it a qualitative nature. While taking interview there were very few questions where students had to give answers by saying either they agreed or disagreed. These kinds of information were numerical and go to under the quantitative research, but in this paper the summary of the collected data is presented in a qualitative nature.

\section{PARTICIPANTS}

The participants of this research were the students of the class six and seven and the teachers. There were 73 to 80 students in almost every class. The researcher observed 3 classes and took interview of 20 students. Two classes were observed of 
standard seven and one class was observed of standard six. The ages of the students were within 13 to 14 years. Most of the participants were quite helpful and were matured enough to understand the purpose of the researcher. The students' curiosity in the research led to their overexcitement regarding the task and interview. As a result the teachers at times found it difficult to maintain order among the students. Nevertheless, both the teachers and the students were polite and very cooperative with the researcher. Like several other Urdu medium schools in Pakistan, the medium of instructions in this school was Urdu. A verbal feedback given was also predominantly in Urdu.

\section{RESEARCH TOOLS}

The researcher used three tools in this research; class observation, students' interview and assessment of students' writing. These three tools were essential in finding out various writing problems different students experienced. I name it the "Triplet Method" to analyze the problematic areas in English language writing skill. Observing various classes, conducting numerous interviews and assessing scripts have all resulted in the authentic collection of information and a successful undertaking of the research. Moreover teachers' speech was also recorded in a mobile phone.

\section{(i) Observation}

Being present in the classes and observing those helped the researcher to get the information she needed to explore the writing problems of the students. The researched needed to establish a connection between what students got from the teachers as input and what they wrote on script as output. Hence, observing the writing classes was a mandatory way of collecting data. Moreover, by observing the classes the researcher could witness the actual faults of teaching that later lead students to face the problems.

\section{(ii) Interviews}

The researcher conducted interviews among 20 students in three classes. Identifying the problems they faced while writing was the main part of this research paper. Direct information from the students helped the researcher to know more about writing problems. Interviewees explained various kind of writing problems they face to the researcher.

\section{(iii) Assessment of Students' Writing}

As it was already mentioned that the researcher wanted to establish a connection between students' input and output so it was mandatory for the researcher to assess some of the scripts of the students. Moreover, script checking also gave a clear view about the writing errors that students made. The researcher checked 20 scripts of those students who were the interviewees.

\section{Data Collection and Analysis}

\section{(i) Class Observation}

In the first class the teacher introduced the topic which was paragraph writing. After explaining the rules the teacher used an example. He talked about a topic "A Teacher" he explained to the students that if a topic like "A teacher" is given to students then the students would write the main idea in the very first line. He also explained to them this way, such as the students should write their thesis statement "a teacher is a person who shares his knowledge with his students". Furthermore, the teacher said them if that sentence is your thesis statement then rest of the paragraph should have the supporting details. The teacher also mentioned to the students that the last line of their paragraph should be the restatement of the thesis statement. Again he made the students aware that they cannot copy the same line of the thesis statement from their topic sentence. The tone would be the same but the language will be different. The teacher gave a topic to the students to write a paragraph and the topic was "A Chair". There was 15 minutes allocated for the students to write a paragraph. The teacher gave them the instruction of writing the paragraph within eight to ten lines. While the students were writing the paragraph the teacher was observing the students and went to them when anyone was asking questions. None of the students asked anything regarding the structure of the paragraph and organizing the information. All of them were asking either the spelling or grammatical rules. The teacher became busy to solve their spelling and grammatical problems. After 15 minutes the teacher and researcher collected the scripts, few of them could complete writing the paragraph and few of them wanted some more time.

In the second class the topic was completing story. This section of writing is considered as the creative writing section. The teachers want the students to write or complete the story with their own words and ideas rather memorizing from the book. From teacher's lecture it was clear that the students already knew the instructions of writing completing story and it was just a revision for them. There would be three parts of completing story, introduction; body paragraph and lastly conclusion. These three parts should have three separate paragraphs. The introduction would be given by the teacher and according to the given introduction the students had to draw a picture of the story and would explain the main story in the body paragraph. Lastly the teacher mentioned that the conclusion would always carry a moral. The students also needed to give the appropriate title based on the story. Moreover, if the students wanted to quote any line or statement then that line should be within inverted comma. After explaining the rules the teacher gave the students a title "The Hare and the Tortoise" to write a story. Usually the introduction of the story was given by the teachers but due to time limitation the teacher gave them the title. While writing the story students seemed confused about spelling and grammatical rules. They were very much conscious about these two things that some of them were keep asking some spelling and 
grammar items to the teachers and to their peers. Students had 15 minutes to complete writing the story. Meanwhile, the researcher asked the teacher the reason behind student not having any question or confusion regarding the title. Then the teacher said that students knew about the title before. There are only three titles of the story given in their syllabus and one of them will surely come to their exam.

In the third class the teacher started his lecture by stating that summary writing is taking the main theme from the passage and writing those ideas in few sentences. Then he pointed five rules of writing summary and later explained the rules one by one orally. The very first rule of summary writing was that the summary would be shorter than the real passage or paragraph. It would be one third of the original passage; students would write the summary within few lines. Secondly, the summary should be written by the theme of the original passage. Students first have to understand the subject or theme of the given passage and then based on that theme they would write the summary. Thirdly, in summary writing there would not be any quotation or example. The teacher pointed that in summary students could not use any moral or any kind of quotation. Using own idea or using ideas from outside the text is strictly prohibited. Again he said that using any kind of example was also not allowed in summary writing. He made it clear to the students that they never could use "as an example" in summary writing. Fourthly, the students could not use any direct line from the given passage. Coping or imitating sentence from the passage was not allowed while writing the summary. He said students to take the main theme from the passage and write the main ideas of the passage in their own language. Lastly the teacher said that whatever they wrote in summary it should be conceptual and structural. In this point he explained that their writing should be structured, there should be logical connection between the sentences. He also wanted the students to be grammatically correct. Once explaining the rules of summary writing was over the teacher gave a task to the students. He selected one passage from the book and told them to summarize that passage.

\section{(ii) Students' Interview}

While answering the question seven students said that writing skill was the most effective skill to express emotion and thought. From their point of view while writing on a topic they could take time to think. They did not need to write instant and that is the reason they can express their thoughts easily. On the other hand three students said through speaking they could express their thought more comfortably. Among ten students eight students said that they face more difficulties with grammatical items while writing on a topic. They became more conscious about their grammatical problems. Two students think that organizing data or creation connection between two kinds of information was the biggest challenge for them while writing. Three kinds of problems were mentioned by the students. Five students said that they often did same grammatical mistakes repeatedly like forget to use "es/s" after third person singular number. Three students mentioned that they faced difficulties while they tried to create relevance within the information. Lastly two students think their marks got deducted due to spelling mistakes. Among ten students eight students think they made fewer mistakes when they got chance to write about an incident by their own language. When they needed to memorize the information, particular vocabulary or grammatical items then they became more conscious and did mistakes. On the other hand, two students think they did better if they had to write on a topic which was memorized. Because then they could use limited grammatical items, information and vocabulary which was already memorized. Except the problem with vocabulary items none of the students think translation was a big deal for them. All of them agreed to the point that if they had experienced an incident or they had the information of a certain topic then they could translate their thought from Urdu to the target language.

There were also ten students in the interview of the second class. The researcher took the students out of the class. Then the interview was arranged in another class. There were also the same ten questions which were asked in the first class. There were five yes/ no questions and five open- ended questions. Writing was the best way to express the thoughts. While writing students got enough time to think about what they are going to write. They could focus on their grammatical confusion and could chose appropriate words to write their thoughts, this is how eight students thought. On the other hand, two students thought that through speaking they can express themselves more quickly and they do not need to be worried about spelling mistakes. Among ten students six students thought they faced grammatical problems more in whole writing task. They faced grammatical problems like tense, using appropriate prepositions, using articles, subject- verb agreement and so on. However, four students faced problem regarding information organization. From their point of view, sometimes they went blank while organizing the information. They could not create coherence between the sentences and words. Ten students mentioned that their biggest problem was grammatical problems while writing. Along with grammatical problems spelling mistakes and lack of vocabularies were big deals for them as they said. Three of them also said that creating logical connection between the sentences was also big trouble for them. Three students out of ten students think they face more problems while writing something from their own ideas. It happened due to lack of confidence and lack of vocabulary. They thought if they have produced a piece of writing by their own words often they failed to organize the whole thing and teacher cannot get what they try to express. On the other hand, seven students think if they have memorized a paragraph or essay then there was a chance to forget it due to their bad memory. They also said memorizing grammatical rules was not their cup of tea. So if they tried to do this they made mistakes. All of the students agreed that they face problems while translating their thoughts from Urdu to English. They again agreed with the point that, not being able of applying grammatical rules and lack of vocabularies were the reasons behind this. They said structure of Urdu sentence is completely different from English sentence that was why they often made mistakes. Moreover, often they could not find a suitable English word for a particular Urdu word due to lack of vocabulary. 
Just like two other classes in this class there were ten interviewees. In this interview there were also the same ten questions which were asked in the first and second class. There were five yes/ no questions and five open- ended questions. All of the interviewee thought that writing was the best way to express their thoughts. While writing they can take enough time and could organize their thoughts properly. Moreover, for them speaking in English was a big thing to do. Most of them were scared of speaking in English because from their point of view they made more mistakes and felt nervous while talking in English. Among ten students seven students thought they face grammatical problems more because there were too many rules to memorize. They thought even if they could translate their ideas from English to Urdu, their main obstacle was applying appropriate grammatical rules. On the other hand three students believed that they faced problems with organizing information. Often they could not organize sentences one after another. Students mentioned lots of problems while answering this question. Individual students mentioned individual problems, like grammatical problems, translation problems, spelling problems and organization problems. Six students thought they faced problems when they wrote with their own ideas. Because they needed to translate from English to Urdu by themselves, they needed to apply correct grammar by themselves moreover they needed to choose appropriate words by themselves. As they were not confident about their capability of producing a piece of writing by their own ideas therefore they prefer to memorize. Four students answered that they did better with their own ideas. Because if they memorized anything then they needed to write exactly what they have memorized and often they forgot information and grammatical rules. They thought they got more marks if they have memorized information. All the interviewees agreed to the point that they faced many problems while translating their thought from English to Urdu. As students were tend to memorize paragraphs, essays, summaries and completing stories therefore they did not need to translate their thoughts. This habit made them unable of translating their own ideas from Urdu to English. Moreover, lack of English vocabularies and different syntax style created problems in translation.

\section{(iii) Students' Script Assessment}

The researcher noticed that except few students, most of the students did not write the thesis statement. In many scripts there was not any specific thesis statement; most of the students wrote some basic information about the given topic "chair". As an example, one of the students started her paragraph by writing that "we use much furniture in our daily life". While writing a paragraph on a chair this cannot be the topic sentence of the paragraph. Students should write their topic sentence related with the topic. Students who wrote their thesis statement did not give the supporting details according to the thesis statement in the body paragraph. As an example, the thesis statement was "a chair is very useful furniture in our life" but the student explained different kinds of chair in her body paragraph rather than explaining the usefulness of the chair. The most common problem in writing was repetition of information. Students wrote one line several times in different language. As an example, "a chair is an useful furniture", "a chair is a necessary furniture", "a chair is very important furniture of our life". Same kind of information was written in several times and it shows they have less knowledge about chair or whatever they have on their mind cannot be translated in English. Grammatical errors were common in every script. Using proper preposition seemed a tough job for the students. As an example, someone wrote, we use chair "into" our dinning space. It shows she had less knowledge about the use of "in" and "into". Many of the students did not restate their thesis statement in different language in the conclusion. Moreover, using irrelevant words were found in several sentences like someone wrote," a chair is seriously useful furniture", she might have tried to mean, "a chair is a useful furniture indeed". The findings from three research instruments suggested that the points the teacher taught about the paragraph writing were not reflected in the students' scripts. Moreover, the writing problems appeared through students' interview was clearly found in their scripts as well.

Apparently all the writings looked very structured, students tried their level best to follow all the rules they knew for writing completing story. However, none of the students tried to draw different picture of the story under the given title "The Hare and the Tortoise". The starting and the ending of the story were almost same in every script. In interview most of the students mentioned that their biggest problem is grammatical problems and it could be understood from their scripts. Apart from grammatical errors, wrong use of punctuations and absence of punctuation was another problem that the researcher found. Moreover, incomplete sentences, wrong choice of words and irrelevant sentences were the common problems in the scripts. In the starting line among ten students, nine students used the word jungle and only one student use the word forest instead of using jungle. It was visible that students did not want to play with words and their learning of vocabulary was very limited. On the other hand, all the scripts showed that students strictly followed the instruction of the teacher. They wrote some starting lines or introduced the characters in the introduction part, elaborated the main story in the body paragraph and lastly ended up the story with a moral. One thing many of the students did not do is many of them did not make separate paragraphs for the three parts. Most of the students started their story with the phrase "once upon a time", and ended the story using the story title. It proves that they seldom used their own ideas while writing the story. Students used simple sentences to write the story and it shows that they have less knowledge about other kinds of sentences. Lastly silly grammatical mistakes like choosing inappropriate tense, degree, voice change and many more were reflected in their scripts. The findings from three research instruments suggest that though the teacher wanted this particular task to be a task of creative writing but his way of teaching did not permit so. He had already given the students a sample of that story and wanted to follow that. Therefore, there was not any creativity in the story writing. As students hardly get any opportunity to write something from their own that is why many students mentioned in interview that they felt unconfident while writing something from their own words and ideas.

The main passage of summary writing was about an ideal teacher who is friendly to her students. The story was about teacher students' relationship and also about the personal life of that teacher. However, most of the students were able to summarize the story according to the instructions. It proved that students did prefer writing which are related to their own life or which they have 
experienced. In other words it was easy for them to learn their lessons from authentic material. On the other hand, some of the students wrote a new story adding their own ideas rather than summarizing the story. As an example, one of them wrote the whole summary by describing her favorite teacher which had no connection with the original passage. In the scripts it was clear the students had severe grammatical problems. They could not use prepositions properly, as an example one of the students wrote; the teacher was very popular with her students. This line showed she did not know the difference between "with" and "among". Moreover, many students did mistake in using "es/s" after third person singular number, chose wrong pro-noun while writing the summary. Though the teacher explained the rules of summary writing in the very beginning many of the students did not followed the rules. In the last sentence many students gave their opinion about an ideal teacher, copied same lines from the original passage which were strictly prohibited in summary writing. Many of the students did not summarize the whole story, repeated same lines and also used inappropriate words in inappropriate places which had happened due to lack of vocabulary. The findings from three research instruments suggest that most of the students were capable of writing summary as summary writing is a very structured and controlled writing. They followed the instructions given by the teacher and could write a good summary. Moreover, six students feel that they can do better if they get opportunity to write something they have memorized and structured and this is the reason they did well in this task.

\section{FINDINGS}

From the analysis, it appeared that the teachers followed GTM (Grammar Translation Method) while teaching the students paragraph and summary writing. The teacher taught the rules first and then presented examples to the students so it can be said that the teacher was using deductive learning method. The teacher was the authoritative figure in the class and there were very few interactions between the teacher and students. From the lecture of the teacher it was quite clear that he wanted the students to be able of writing a paragraph accurately. For teaching the students' accurate paragraph writing he emphasized more on grammar and literary language. While he went to check what they were writing, he corrected the use of articles and prepositions. Grammar Translation Method focuses only teaching and learning of rules. From GTM perspective learning a language means learning all grammatical rules. In GTM accuracy is more important than fluency. Students need to learn all grammatical items correctly they do not need to be fluent in use the use of grammar while talking. In GTM method deductive learning is a must, student need to learn rules and definitions first and later they learn examples. Through this method student can learn grammatical rules correctly and they do well in writing. This method is good for beginners and for large class also, it required fewer resources. On the other hand, in this method teacher is the authoritative figure to make decisions and the participation of learners is very less. Teachers can simply find out error characteristics from students' writing. There are eight major problems that students face in error characteristics and they are, spelling problems, pronoun usage, agreement between subject and predicate, the avoidance of run-on sentence, capitalization, punctuation, usage of slang or nonstandard terms and modification problems. But if there is no mistake in writing still that particular writing cannot be considered as a good piece of writing. There are some non-error characteristics which make difference between skilled writing and non-skilled writing and they are density of ideas, variety of referents and variety of expression in repeated concepts. Focusing only on grammatical rules, correct spelling and appropriate use of vocabulary is not enough to produce a good piece of writing. Even if a student writes a piece of writing without any grammatically error but still cannot create any sense in his writing then it will not be considered as a skilled writing piece.

From the result of interview it was quite clear that most of the students believed that they could express their thoughts more efficiently through writing. From their point of view they could take time and could state their emotions and thoughts properly. From their perspective they could not express their thoughts through speaking fluently, as they had to deliver their thoughts instantly and make mistakes. They also mentioned that through writing they could have good command over English language. There should be a balance between grammar-oriented and communication-oriented activities in the successful foreign language classroom. The teachers should not only focus on grammar rather they should focus on both grammatical rules and content. Moreover, they should find out whether the students are able to communicate with the reader through their writings or not. That means, whether they are able to make sense in their writings or not. While checking the scripts the researcher noticed that the students' writing was not organized. Repetition of information, absence of thesis statement, using irrelevant information, lack of creative writing and producing controlled writing and lastly many silly grammatical mistakes were seen in their scripts. Students wrote some random information about the topic and constructed their paragraph. Irrelevant information and repetition of information was very common in every script. As the teacher gave less importance on those issues therefore the students were also less concerned. The researcher asked the teachers of each class to check two scripts to observe their way of giving feedback. Teachers were focusing more on grammatical rules rather than the content. They were finding grammatical mistakes, without giving the concern to the fact that students wrote irrelevant information and there was not any synchronization of information in the scripts. Giving feedback only on the use of grammatical rules is not enough to improve students' writing performance. Teachers should provide the feedback on the content as well. If the teachers can provide feedback on these two features then the students will be able to find their writing problems by themselves. One of the reasons behind students' persistent writing problems is the feedback. The feedback strategies employed by the teachers are not precise and motivational. They only deduct marks and point out the reason of deducting marks. They do not comment on the quality of the writing and moreover do not correct the answer with the solution. Therefore, students become unaware of their problem. Feedback on writing task should be specific and motivational. The teachers should provide the feedback such way that helps students to identify their problems and encourages them to solve it by themselves. 


\section{CONCLUSION}

After analyzing all the findings the study can be concluded by stating that the secondary level students of Urdu medium school prefer writing task more than speaking task, since they feel more comfortable to express their thoughts and ideas through writing tasks. Moreover, memorizing grammatical rules is a challenge for them because there are differences between English grammar and Urdu grammar. As their writing performance is valued based on the correct use of grammatical rules, they focus more on this aspect. They believe that if they can produce a writing piece without any grammatical error then they are good in writing. On the other hand, some of the students thought that they are bad in terms of organizing the information; some students thought they are not good in creative writing because they are much used to in controlled writing and some of the students thought they face problems while doing translation due to the differences in sentence structures between the two languages. The research would have had more impact if the researcher could get the opportunity to visit more Urdu medium schools. There was limitation of time to visit more than one school; therefore the researcher had to choose one school and observed three different classes. If the researcher could get the opportunity to observe different schools then the finding would have been more authentic and there would have more variation of data For future investigations, the researcher suggests to conduct a more detailed analysis of the topic, as it is an important area of second language learning. Interviews of both teachers and students can be added to make the research more authentic. To conclude the paper, it can be stated that students of Urdu medium schools have different writing problems such as grammatical errors, unorganized and irrelevant information, spelling mistakes, inappropriate use of vocabularies and etc. Their problems can be solved if they get the proper guideline and feedback from the teachers.

\section{REFERENCES}

1. Tirumalesh, K. V. (1991). Writing-English versus Writing-in-English: New Notes on an Old Theme. Economic and Political Weekly, 26(47), 2670-2672.

2. Ur, P. (1996). A course in language teaching: Practice and theory. Ernst Klett Sprachen.

3. Widodo, H. P. (2006). Approaches and procedures for teaching grammar. English Teaching: Practice \& Critique (University of Waikato), 5(1).

4. Chen, Y.-S., \& Su, S.-W. (2012). A genre-based approach to teaching EFL summary writing. ELT Journal, 66(2), $184-192$.

5. Manchón, R. (Ed.). (2011). Learning-to-write and writing-to-learn in an additional language (Vol. 31). John Benjamins Publishing.

6. Lund, R. E. (2015). Handwriting as a tool for learning in ELT. ELT Journal.

7. Coe, R. M., \& Gutierrez, K. (1981). Using problem-solving procedures and process analysis to help students with writing problems. College Composition and Communication, 32(3), 262-271.

8. Larsen-Freeman, D. (2000). Techniques and principles in language teaching (2nd ed.). Oxford, England: Oxford University Press.

9. Marzano, R. J. (1982). Identifying various types of student writing problems. Journal of Reading, 25(5), 408-411

10. Flower, L. S. (1979). Writer-based prose: a cognitive basis for problems in writing. College English, 41(1), 19-37.

11. Evans, B. (1959). Writing and Composing. The English Journal, 48(1), 12-20.

12. VanPatten, B. (1992). Second-language-acquisition research and foreign language teaching, Part 2. ADFL Bulletin, 23(3), $23-27$.

13. Tomiyama, M. (1980). Grammatical errors and communication breakdown. TESOL Quarterly, 14(2), 71-79.

14. Lagerberg, R. (1995). Teaching Cases to Students without a Grammatical Background. New Zealand Slavonic Journal, 111-120. 